\title{
Development of Bi-Langmuir model on the sorption of cadmium onto waste foundry sand: Effects of initial $\mathrm{pH}$ and temperature
}

\author{
Noora Saad ${ }^{1}$, Ziad T. Abd Ali $^{2}$, Laith A. Naji ${ }^{2}$, Ayad A.A.H. Faisal ${ }^{\dagger}$, Nadhir Al-Ansari ${ }^{3}$ \\ ${ }^{1}$ Department of Civil Engineering, Al-Nahrain University, Baghdad, Iraq \\ ${ }^{2}$ Department of Environmental Engineering, College of Engineering, University of Baghdad, Iraq \\ ${ }^{3}$ Department of Civil, Environmental and Natural Resources Engineering, Lulea University of Technology, 97187 Lulea, Sweden
}

\begin{abstract}
The present study develops the sorption model for simulating the effects of $\mathrm{pH}$ and temperature on the uptake of cadmium from contaminated water using waste foundry sand (WFS) by allowing the variation of the maximum adsorption capacity and affinity constant. The presence of two acidic functional groups with the same or different affinity is the basis in the derivation of the two models; Model 1 and Model 2 respectively. The developed Bi-Langmuir model with different affinity (Model 2) has a remarkable ability in the description of process under consideration with coefficient of determination $>0.9838$ and sum of squared error $<0.08514$. This result is proved by FTIR test where the weak acids responsible of cadmium ions removal using WFS sorbent can be represented by surface silanol $(\mathrm{O}-\mathrm{H})$ functional groups.
\end{abstract}

Keywords: Cadmium, Foundry sand, Modified langmuir model, Simulation, Sorption

\section{Introduction}

Metallic elements with a relatively high density that greater than of the water's density are defined the "heavy metals" [1]. Recently, an increasing ecological concern related with the environment contamination by heavy metals has been recognized. Due to the mobile nature of these metals, they can be reached to the different geological formations and cause a significant contamination for subsurface environment especially the groundwater where the front of the contamination may be propagated with the time to find its pathway for surface water resources [2]. Erosion, weathering or volcanic eruptions are considered the natural sources for pollution of groundwater with heavy metals as reported by previous studies such as $[3,4]$. However, the human activities such as geogenic, industrial, agricultural, pharmaceutical, industrial production and use, domestic effluents and solids waste are represented the main processes that resulted the high concentrations of heavy metals [5-9]. In addition, the leachates resulted from agriculture sites or surface runoff can infiltrate to the groundwater and cause a potential pollu- tion for subsurface media.

The previous studies reveal that the remediation of contaminated groundwater using conventional techniques such as "pump and treat" or "impermeable barriers" is required high cost. Accordingly, permeable reactive barrier (PRB) is an innovative technology that applied within the polluted site to retain the contaminants by the reactive material of the barrier for restricting the migration of dissolved plume [10, 11]. The migration of the metals within the PRB is governed by the "advection-dispersion-reaction equation" where the reaction (i.e. sorption) process plays a great role in the containment of the contaminant within the reactive medium of the barrier. The sorption process can be formulated by different models like Freundlich, Langmuir etc. where these models are very helpful in the simulation of the experimental data measured at certain values of $\mathrm{pH}$ and temperature. However, the common status in the subsurface environment that the $\mathrm{pH}$ and temperature are varied in response to the external factors and the reflection of this change in the isotherm model can be considered a unique task of this study. The developed model can be incorporated in
This is an Open Access article distributed under the terms of the Creative Commons Attribution Non-Commercial License (http://creativecommons.org/licenses/by-nc/3.0/) which permits unrestricted non-commercial use, distribution, and reproduction in any medium, provided the original work is properly cited.

Copyright (C) 2020 Korean Society of Environmental Engineers
Received June 28, 2019 Accepted September 02, 2019

${ }^{\dagger}$ Corresponding author

Email: yadabedalhamzafaisal@yahoo.com

Tel: +9647904208688

Orcid: 0000-0002-6640-1574 
the future with the advection-dispersion equation as sink term to describe the contaminant transport under the influences of $\mathrm{pH}$ and temperature of the flowing water.

Many studies have been achieved to fit the isotherm models to experimental datasets measured at different conditions. In this direction, Langmuir isotherm was used to represent a set of laboratory measurements collected at various values of $\mathrm{pH}$ where the regression related between the adsorption capacity and $\mathrm{pH}$ was developed [12, 13]. Adsorption of arsenic from aqueous solutions onto iron oxide can be represented by a modified Langmuir isotherm [14]. Also, the pH-dependent bio-sorption using marine macro-algae for removal of heavy metals with aid of the functional groups can be formulated by modified Langmuir model [15]. A set of empirical and semi-empirical expressions based on the Langmuir isotherm were developed to describe the removal of copper onto the calcium alginate and sphaerotilus natans sorbents under the effect of $\mathrm{pH}$ [16]. Further, column tests to monitor the reduction of $\mathrm{Cr}(\mathrm{VI})$ from contaminated water onto scrap iron were conducted with the values of $\mathrm{pH}$ varied from 2.00 to 7.30 . The results signified that the maximum reduction capacity has value of $19.2 \mathrm{mg} \mathrm{Cr}(\mathrm{VI}) / \mathrm{g}$ iron at $\mathrm{pH}$ equal to 2.50, however, it is decreased due to increase of $\mathrm{pH}$ value [17]. Freundlich and Langmuir models were collected in one form named as the modified Langmuir-Freundlich isotherm and the influence of $\mathrm{pH}$ on the adsorption process in the batch tests can be describe by this isotherm. The values of affinity constants in this formula were correlated linearly with $\mathrm{pH}$ of aqueous solutions. The adsorption measurements resulted from interaction of goethite-coated sand and pure goethite with the arsenic contaminant was used for validation of developed formula [18]. In addition, the Langmuir model was developed for description the interaction of olive pips and aqueous solution contaminated with copper under the variation of initial $\mathrm{pH}$. The influence of $\mathrm{pH}$ was represented by linear and nonlinear relationships for the maximum adsorption capacity and affinity constant respectively as a function of the initial $\mathrm{pH}$. This isotherm was incorporated with solute transport equation to find the distribution of contaminant through the column tests under the effect of initial pH [19]. Finally, the Freundlich model was developed for predicting the adsorption capacity of quinolone by powdered activated carbon at different $\mathrm{pH}$ values. This model had excellent prediction capabilities under different laboratory scenarios [20].

The Bi-Langmuir isotherm was suggested for first time by Graham in (1953) [21] and the author assumed that the adsorption onto the surface composed by patches of two different homogeneous surfaces has independent behaviour. On each type of site, the same Langmuir principles of local adsorption are applied without adsorbate - adsorbate interactions. Accordingly, the present work is aimed to develop the Bi-Langmuir isotherm model for predicting the $\mathrm{pH}$ and temperature-adsorption effects which can be verified using experimental data of cadmium-waste foundry sand (WFS) interaction. This model opens new horizons for simulating the effects of $\mathrm{pH}$ and temperature on the values of retardation factor and, consequently, the longevity of the PRB using available codes of contaminant transport such as COMSOL Multiphysics 3.5a.

\section{Materials and Methods}

\subsection{Preparation of Sorbent and Contaminant}

WFS can be used as reactive material in the batch experiments and this material is resulted from steel foundry industry as byproduct. The particle size distribution of WFS ranged from 0.08 to $9 \mathrm{~mm}$ with median size of $320 \mu \mathrm{m}$, effective size of $180 \mu \mathrm{m}$, and uniformity coefficient of 1.94. The choice of WFS is mainly based on the presence of silica in its composition; therefore, the functional groups of silica $(S i-O H$ and $(O H)$ ) have able to remove of cadmium ions where the $\mathrm{pH}$ and temperature play a significant role in the exchange of proton from these groups. Aqueous solutions were contaminated with cadmium to simulate the pollution of the groundwater. Stock solution with concentration of $1,000 \mathrm{mg} / \mathrm{L}$ can be prepared using $\mathrm{Cd}\left(\mathrm{NO}_{3}\right)_{2} \cdot 4 \mathrm{H}_{2} \mathrm{O}$ (manufactured by India) and this solution was used to obtain the required concentration by dilution.

\subsection{Sorption Tests}

Experimental batch tests were carried out under different values of initial $\mathrm{pH}$ of $(3,4,4.5,5,6)$, temperature of $\left(30,40\right.$, and $\left.50^{\circ} \mathrm{C}\right)$, and initial cadmium concentration $\left(C_{o}\right)$ of $(10,50,100$, and 200 $\mathrm{mg} / \mathrm{L}$ ). The $50 \mathrm{~mL}$ of cadmium solution was distributed onto the series of the flasks and certain quantity of the reactive material (2.5 g) was added for each flask. Subsequently, continuous agitation of these flasks was achieved for duration reached to $3 \mathrm{~h}$ using orbital shaker (Edmund Buhler SM25, German) with an agitation speed of $200 \mathrm{rpm}$. The aqueous solution was filtered at the end of each test and the measurement of its final $\mathrm{pH}$ can be achieved. Also, the remaining concentration of the cadmium ions $\left(C_{e}\right)$ can be measured by atomic absorption spectrophotometer (AAS) (AA-7000 Shimadzu, Japan). Additional tests for interaction of uncontaminated aqueous solution with WFS were conducted under the same conditions of initial $\mathrm{pH}$ to investigate the variation of final $\mathrm{pH}$ in comparison with final $\mathrm{pH}$ of the contaminated solution. The quantity of cadmium sorbed on the reactive material, $q_{e}$, is calculated by:

$$
q_{e}=\left(C_{o}-C_{e}\right) \frac{\mathrm{v}}{m}
$$

where $\mathrm{V}$ is the volume of aqueous solution (L) and $m$ is the WFS added to the flask (g). The measured sorption data have been fitted with Freundlich, Langmuir and Temkin models using non-linear regression method for calculating the parameters of the models by Excel 2016.

\subsection{Sorption Isotherm Models}

Measured equilibrium data were fitted by "two parameter isotherms" including Freundlich, Langmuir, and Temkin. A brief review of the adopted models is inserted below [22, 23]:

- Freundlich model (1906) is applicable for multilayer sorption and heterogeneous surfaces:

$$
q_{e}=a_{F} C_{e}^{\frac{1}{n}}
$$


where $a_{F}$ is the constant related with the maximum adsorption capacity of the sorbent and $1 / n(<1)$ is the intensity of sorption.

- Langmuir model (1916) is applicable for uniform energies of sorption onto the sorbent surface:

$$
q_{e}=\frac{q_{\max } b C_{e}}{1+b c_{e}}
$$

where $q_{\max }$ is the maximum sorption capacity (mg/g) and $b$ is the affinity of the metal ions towards reactive material.

- Temkin model is assumed that the adsorption is described by a uniform distribution of the binding energies up to maximum binding energy [24] as below:

$$
=B \ln K_{T}+B \ln C_{e}
$$

where $K_{T}$ is the equilibrium binding constant (L/mg) and B is the constant related to the heat of sorption $(\mathrm{J} / \mathrm{mol})$.

\section{Results and Discussion}

\subsection{Equilibrium Study}

Fig. 1 reveals that the removal percentage of the cadmium ions from contaminated water increases due to an increase in the initial $\mathrm{pH}$ values for same value of concentration and temperature until arrived to maximum value at initial $\mathrm{pH}$ of 4.5 and, thereafter, the removal was decreased. Protonation and deprotonation of the acidic and basic groups for WFS are mainly caused of this behavior, so, the interaction between metal ions and sorbent as a function of the initial $\mathrm{pH}$ can be influenced significantly [25-27]. The small value of the removal percentage in comparison to the best removal efficiency can be attributed to inactivation of binding sites in the basic conditions [28]. The initial $\mathrm{pH}$ of the aqueous solution is tended to rise from acidic state $(=3)$ with progress of the operation process but it becomes almost constant at higher $\mathrm{pH}$. This trend is resulted from the competition between the cations and protons on the surfaces of the active sites up to a particular point where the protons have been removed from the aqueous solution [29]. In contrast, with an initial alkaline solution $(\mathrm{pH}=6)$, the trend progresses downward as the operation proceeds further until the $\mathrm{pH}$ becomes practically constant. This behavior may be correlated to the presence of substantial amount of the $\mathrm{Cd}(\mathrm{OH})^{+}$ions that are retained by the solid, as well as to the precipitation of $\mathrm{Cd}(\mathrm{OH})_{2}$, that occurs at an alkaline $\mathrm{pH}$, removing the hydroxyl groups from the aqueous solution, resulting in the drop of $\mathrm{pH}$ values [30-32]. Fig. 1 signifies that the removal efficiency of cadmium was decreased with the increase of the initial concentration [33]. Also, it seems from this figure that the best values of the initial $\mathrm{pH}$ and temperature to achieve the maximum removal efficiency were 4.5 and $30^{\circ} \mathrm{C}$, respectively.

The Freundlich, Langmuir and Temkin isotherm models, described previously, were employed for fitting the sorption measurements using nonlinear fitting of the regression and the constants of these models is inserted in Table 1. Statistical measures such as coefficient of determination $\left(R^{2}\right)$ and the sum of squared error (SSE) are determined for evaluating the concurrence between
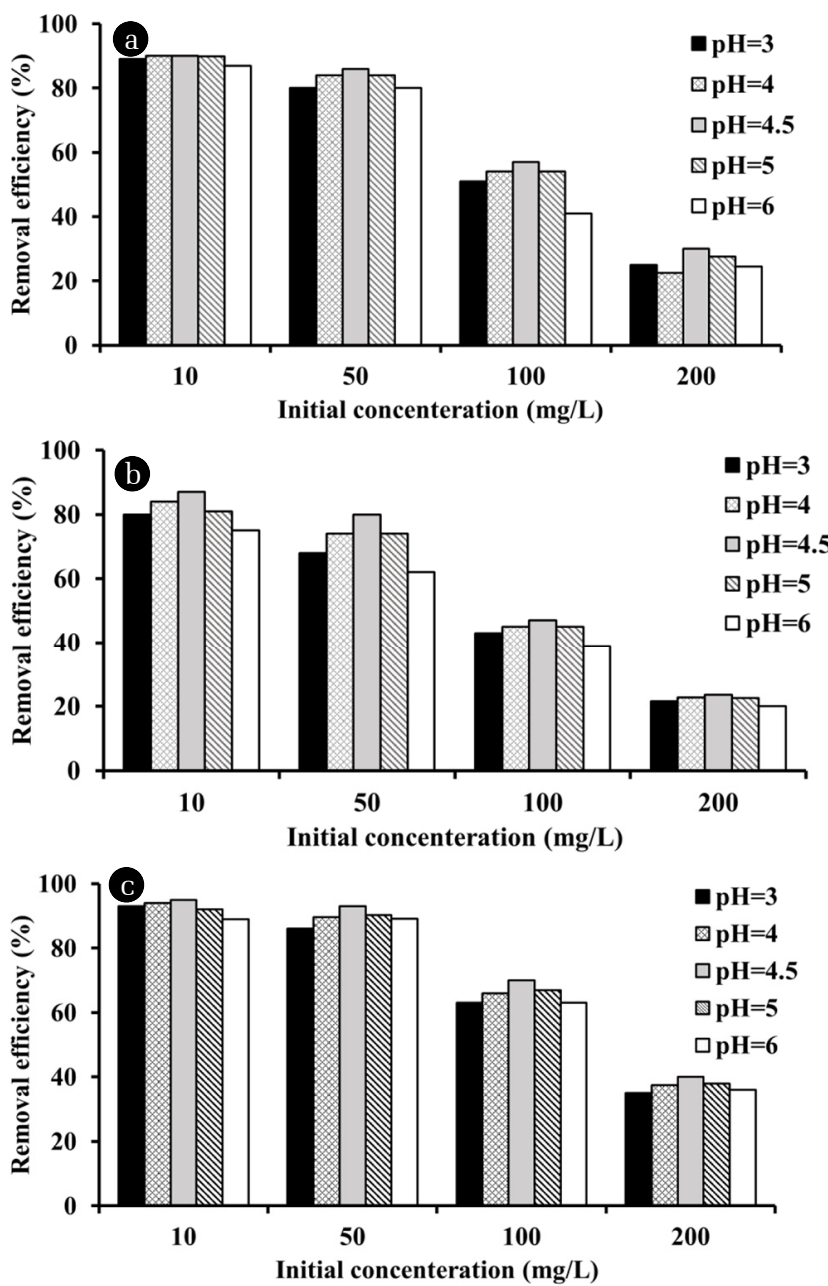

Fig. 1. Removal efficiency of cadmium by WFS as a function of initial concentration, initial $\mathrm{pH}$ and temperature $\left(\mathrm{pH}=3-6 ; \mathrm{C}_{\mathrm{o}}=\right.$ $10-200 \mathrm{mg} / \mathrm{L} ;$ WFS dosage $=2.5 \mathrm{~g} / 50 \mathrm{~mL}$; agitation speed $=$ 250 rpm; $\mathrm{T}=30-50^{\circ} \mathrm{C}$. (a) $\mathrm{T}=50^{\circ} \mathrm{C}$, (b) $\mathrm{T}=40^{\circ} \mathrm{C}$, (c) $\mathrm{T}=30^{\circ} \mathrm{C}$.

experimental data and isotherm models. It is clear that the Langmuir model has a good ability to describe the experimental data under different operational conditions adopted in the present investigation in comparison with Freundlich and Temkin models. This certified that the fitting of heterogeneous mode of sorption with the Freundlich model cannot be supported. In addition, this table signified that there is a dramatic change in the value of Temkin isotherm-binding constant (i.e. adsorption activity) as a function of initial $\mathrm{pH}$ value for the same temperature. Finally, the application of the Langmuir model on the measured data means that the homogeneous monolayer mode of sorption is predominant for situation under consideration with $\mathrm{R}^{2}$ not less than 0.972 .

\subsection{Development of Bi-Langmuir Model}

To develop the Bi-Langmuir model that taken the effects of initial $\mathrm{pH}$ and temperature into account, a set of relationships simulated initial $\mathrm{pH}$ and temperature-dependent sorption effects 
Table 1. Constants of Freundlich, Langmuir, and Temkin Isotherm Models Using Non-linear Fitting for Sorption of Cadmium onto WFS

\begin{tabular}{|c|c|c|c|c|c|c|c|c|c|c|c|c|}
\hline \multirow{3}{*}{ pH } & \multicolumn{4}{|c|}{ Freundlich isotherm } & \multicolumn{4}{|c|}{ Langmuir isotherm } & \multicolumn{4}{|c|}{ Temkin isotherm } \\
\hline & \multirow{2}{*}{ Parameter } & \multicolumn{3}{|c|}{ Temperature $\left({ }^{\circ} \mathrm{C}\right)$} & \multirow{2}{*}{ Parameter } & \multicolumn{3}{|c|}{ Temperature $\left({ }^{\circ} \mathrm{C}\right)$} & \multirow{2}{*}{ Parameter } & \multicolumn{3}{|c|}{ Temperature $\left({ }^{\circ} \mathrm{C}\right)$} \\
\hline & & $\mathbf{5 0}$ & 40 & 30 & & 50 & 40 & 30 & & $\mathbf{5 0}$ & 40 & 30 \\
\hline \multirow{4}{*}{3} & $a_{F}$ & 0.4508 & 0.3869 & 0.2793 & $q_{\max }$ & 1.4397 & 1.0722 & 0.9377 & $B$ & 0.2381 & 0.1737 & 0.1678 \\
\hline & $n$ & 4.0205 & 4.6981 & 4.0911 & $b$ & 0.2095 & 0.2468 & 0.1403 & $K_{T}$ & 3.9548 & 4.4316 & 1.9608 \\
\hline & $R^{2}$ & 0.8886 & 0.7731 & 0.799 & $R^{2}$ & 0.9996 & 0.9882 & 0.9875 & $R^{2}$ & 0.9766 & 0.8853 & 0.9083 \\
\hline & SSE* $^{*}$ & 0.1041 & 0.1088 & 0.0684 & $\mathrm{SSE}^{*}$ & 0.0004 & 0.0068 & 0.0051 & SSE & 0.0208 & 0.0534 & 0.0302 \\
\hline \multirow{4}{*}{4} & $a_{F}$ & 0.4969 & 0.446 & 0.3228 & $q_{\max }$ & 1.5153 & 1.0433 & 0.9756 & $B$ & 0.2478 & 0.1529 & 0.1666 \\
\hline & $n$ & 4.1078 & 5.721 & 4.4081 & $b$ & 0.2627 & 0.3486 & 0.1866 & $K_{T}$ & 4.7881 & 8.7343 & 2.8806 \\
\hline & $R^{2}$ & 0.8873 & 0.6089 & 0.7799 & $R^{2}$ & 0.9967 & 0.9253 & 0.9855 & $R^{2}$ & 0.9747 & 0.7267 & 0.8897 \\
\hline & SEE & 0.1203 & 0.1852 & 0.0832 & SSE & 0.0035 & 0.0383 & 0.0068 & SSE & 0.0258 & 0.1269 & 0.0405 \\
\hline \multirow{4}{*}{4.5} & $a_{F}$ & 0.5606 & 0.4228 & 0.3736 & $q_{\max }$ & 1.5962 & 1.1756 & 1.0048 & $B$ & 0.2553 & 0.1896 & 0.1613 \\
\hline & $n$ & 4.2835 & 4.5255 & 4.8716 & $b$ & 0.3577 & 0.2959 & 0.2575 & $K_{T}$ & 6.3386 & 5.217 & 4.6303 \\
\hline & $R^{2}$ & 0.875 & 0.8339 & 0.7323 & $R^{2}$ & 0.9926 & 0.9686 & 0.9728 & $R^{2}$ & 0.9638 & 0.9181 & 0.8428 \\
\hline & SSE & 0.1529 & 0.0935 & 0.1099 & SSE & 0.0098 & 0.0185 & 0.0135 & SSE & 0.0426 & 0.0451 & 0.0631 \\
\hline \multirow{4}{*}{5} & $a_{F}$ & 0.4919 & 0.417 & 0.3158 & $q_{\max }$ & 1.5498 & 1.1588 & 0.9788 & $B$ & 0.2639 & 0.1877 & 0.171 \\
\hline & $n$ & 4.0136 & 4.6403 & 4.3505 & $b$ & 0.247 & 0.2664 & 0.1697 & $K_{T}$ & 3.7325 & 4.653 & 2.4264 \\
\hline & $R^{2}$ & 0.8651 & 0.7858 & 0.7533 & $R^{2}$ & 0.9924 & 0.9894 & 0.9731 & $R^{2}$ & 0.9585 & 0.8944 & 0.8663 \\
\hline & SSE & 0.1487 & 0.1223 & 0.0935 & SSE & 0.01 & 0.0079 & 0.0124 & SSE & 0.044 & 0.0586 & 0.0493 \\
\hline \multirow{4}{*}{6} & $a_{F}$ & 0.4513 & 0.3485 & 0.2342 & $q_{\max }$ & 1.4699 & 0.9674 & 0.8744 & $B$ & 0.2578 & 0.1564 & 0.1628 \\
\hline & $n$ & 3.9486 & 4.6561 & 3.8133 & $b$ & 0.2232 & 0.2685 & 0.1106 & $K_{T}$ & 2.987 & 4.5644 & 1.4152 \\
\hline & $R^{2}$ & 0.8451 & 0.7607 & 0.8227 & $R^{2}$ & 0.9794 & 0.9422 & 0.9903 & $R^{2}$ & 0.9379 & 0.8505 & 0.9273 \\
\hline & SSE & 0.1493 & 0.0923 & 0.0505 & SSE & 0.0234 & 0.0243 & 0.0034 & SSE & 0.0581 & 0.0567 & 0.02 \\
\hline
\end{tabular}

* sum of squared error $\left(S S E=\sum\left(q_{\text {experiment }}-q_{\text {predicted }}\right)^{2}\right)$

are derived with the aid of experimental measurements for interactions of WFS and aqueous solution contaminated with cadmium as described below:

Affinity constant: The activation energy of metal sorption onto the sorbent can be calculated by the relationships [34, 35]:

$$
b(p H, T)=k \cdot(p H) e^{\left(\frac{Q}{R T}\right)}
$$

where $k$. is the affinity of the sorbate at reference temperature which can be changed with $\mathrm{pH}(\mathrm{L} / \mathrm{mg})$ and $Q$ is the heat of sorption (the difference between the activation energies necessary for desorption and sorption).

The calculated values of $b$ for different values of initial $\mathrm{pH}$ and temperature mentioned in Table 1 can be used for fitting the Eq. (5) using nonlinear regression and finding the values of $k$. as function of initial $\mathrm{pH}$. Then, the power relationships are more representative regressions to represent the variation of $k$. with initial $\mathrm{pH}$ based on the coefficient of determination as explained below:
For initial $\mathrm{pH}<4.5 ; \mathrm{k} .=\mathrm{e}^{(0.281 \mathrm{pH}-1.7402)}, \mathrm{R}^{2}=0.9996$

For initial $\mathrm{pH}>4.5 ; \mathrm{k} .=\mathrm{e}^{(-0.2427 \mathrm{pH}+0.5471)}, \mathrm{R}^{2}=0.8198$

This means that the general formula for describing the relationships related between of $k$. and initial $\mathrm{pH}$ can be written as follows:

$$
\mathrm{k} .(p H)=e^{a p H+b}
$$

Eq. (8) can be substituted into the Eq. (5) to yield the following expression:

$$
b(p H, T)=e^{\left(\frac{Q}{R T}\right)+a p H+b}
$$

Maximum sorption capacity: This constant $\left(q_{\max }\right)$ is varied as a function to the initial $\mathrm{pH}$ and temperature by assuming that there are two functional weakly acid groups responsible of sorption process [15]. The $q_{\max }$ can be written using "subsequent additions method" and the present study derived two forms for $q_{\max }$ as below: 
A) The two functional groups have the same affinity and, accordingly, $q_{\max }$ take the following form:

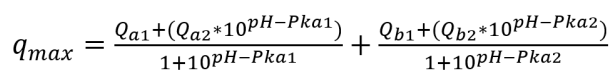

where $Q_{a 1}, Q_{a 2}, Q_{b 1}$ and $Q_{b 2}$ are the maximum adsorption capacities for protonated ( $A H$ and $B H$ ) and deprotonated $\left(A^{-}\right.$and $B^{-}$) forms of the two functional groups. The equilibrium of protonated and deprotonated forms of the functional groups can be described as follows:

$$
\begin{array}{cc}
A H \leftrightarrow A^{-}+H^{+} & B H \leftrightarrow B^{-}+H^{+} \\
k_{a 1}=\frac{\left[A^{-}\right]\left[H^{+}\right]}{[A H]} & k_{a 2}=\frac{\left[B^{-}\right]\left[H^{+}\right]}{[B H]} \\
P k_{a 1}=-\log _{10}\left(k_{a 1}\right) & P k_{a 2}=-\log _{10}\left(k_{a 2}\right)
\end{array}
$$

where $k_{a 1}$ and $k_{a 2}$ are the apparent equilibrium constants.

The equilibrium constants are expressed as the difference between entropy change $\left(\triangle S^{\circ}\right)$, as a function of temperature, and enthalpy change $\left(\Delta H^{\circ}\right)$ for the described reaction [34, 36]. The relationship between $k_{a}$ and temperature was described using the van't Hoff equation:

$$
k_{a}=e^{\frac{\Delta S^{\circ}}{R}-\frac{\Delta H^{\circ}}{R T}}
$$

Combination of Eq. (14) and Eq. (13), the following equation can be written:

$$
P k_{a 1}=\left(\frac{\Delta S 1^{\circ}}{\ln (10) R}-\frac{\Delta H 1^{\circ}}{\ln (10) R T}\right) \quad \text { and } P k_{a 2}=\left(\frac{\Delta S 2^{\circ}}{\ln (10) R}-\frac{\Delta H 2^{\circ}}{\ln (10) R T}\right)
$$

Combination of Eq. (10) with Eq. (15) will produce the following equation:

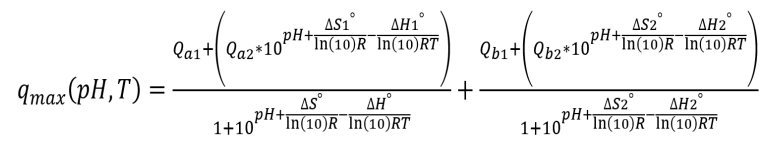

where $\triangle H 1^{\circ}$ and $\triangle H 2^{\circ}$ are the enthalpy change, while $\triangle S$ $1^{\circ}$ and $\triangle S 2^{\circ}$ are the entropy change of the first and second reactions, respectively.

Hence, the first form (Model 1) of Bi-Langmuir model for two weakly acid functional groups with same affinity can be written as follows:

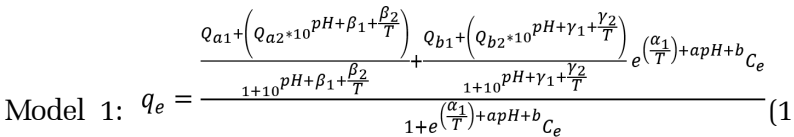

where $\beta_{1}=\frac{\Delta S 1^{\circ}}{\ln (10) R}, \beta_{2}=\frac{-\Delta H 1^{\circ}}{\ln (10) R}, \gamma_{1}=\frac{\Delta S 2^{\circ}}{\ln (10) R}, \gamma_{2}=\frac{\Delta H 2^{\circ}}{\ln (10) R}, \alpha_{1}=\frac{Q}{R}$

B) The two functional groups have the different affinity and, accordingly, $q_{\max }$ take the following form:

$$
\begin{aligned}
& q_{1 e}=\frac{q_{1 \max } b_{1} C_{e}}{1+b_{1} C_{e}} \\
& q_{2 e}=\frac{q_{2 \max } b_{2} C_{e}}{1+b_{2} C_{e}}
\end{aligned}
$$

where $q_{1 \max }$ and $q_{2 \max }$ are the maximum sorption capacities (mg/g) for first and second functional groups, respectively. Similarly, the affinity of the first and second functional groups towards sorbent is denoted as $b_{1}$ and $b_{2}$, respectively. The sum of $q_{1 e}$ and $q_{2 e}$ is equal to $q_{e}$ as follows:

$$
\begin{gathered}
q_{e}=q_{1 e}+q_{2 e} \\
q_{e}=\frac{q_{1 \max } b_{1} C_{e}}{1+b_{1} C_{e}}+\frac{q_{2 m a x} b_{2} C_{e}}{1+b_{2} C_{e}} \\
q_{e}=\frac{\frac{Q_{a 1}+\left(Q_{a 2} * 10^{p H-P k a 1}\right)}{1+10^{p H-P k a 1}} b_{1} C_{e}}{1+b_{1} C_{e}}+\frac{\frac{Q_{b 1}+\left(Q_{b 2} * 10^{p H-P k a 2}\right)}{1+10^{p H-P k a 2}} b_{2} C_{e}}{1+b_{2} C_{e}}
\end{gathered}
$$

Assuming $q_{\max }(b)$ is a function to the affinity of the sorbate (b), then:

$$
q_{\max }(b)=\frac{Q_{1}^{\backslash}+\left(Q_{2}^{\backslash} * b\right)}{1+b}
$$

where $Q_{1}^{\backslash}$ and $Q_{2}^{\backslash}$, are constant. Consequently, Eq. (23) can be written as follows and this is the second form (Model 2) of Bi-Langmuir model for two weakly acid functional groups with different affinity:
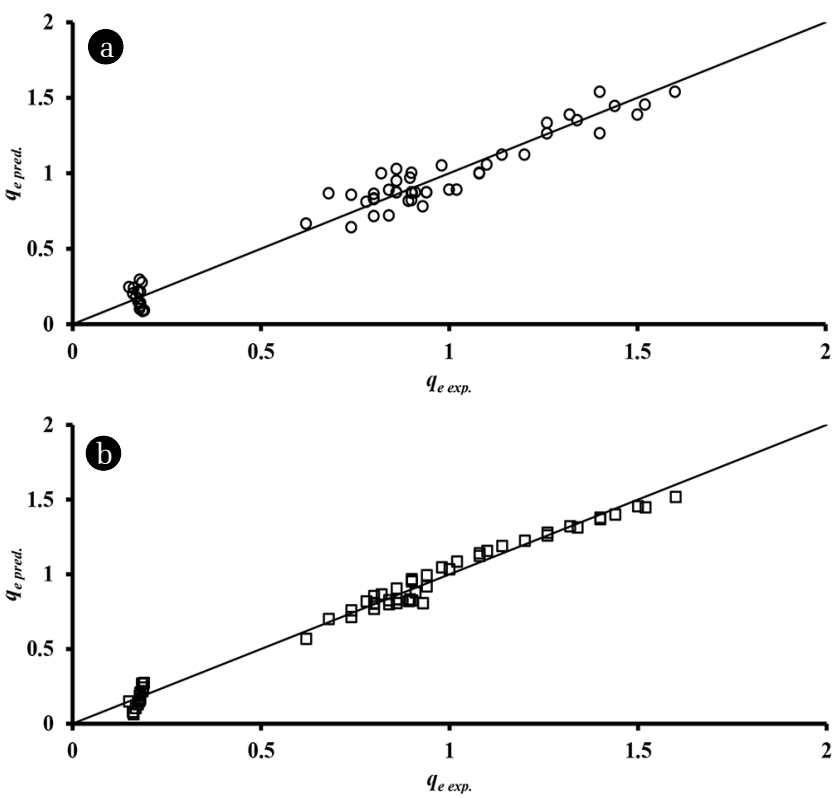

Fig. 2. Scatter diagram ( $q_{\mathrm{e}}$ exp. vs. $\mathrm{q}_{\mathrm{e} \text { pred. }}$ ) for cadmium sorption at different values of $\mathrm{pH}$ and temperature using developed models 1 and 2. (a) Model 1, (b) Model 2. 
Table 2. Constants of the Models Developed in the Present Study for Cadmium Sorption onto Waste Foundry Sand Using Non-linear Regression Analysis

\begin{tabular}{|c|c|c|c|}
\hline \multicolumn{2}{|c|}{ Initial pH } & $\leq 4.5$ & $>4.5$ \\
\hline \multirow{13}{*}{ Model 1} & $Q_{a 1}$ & 0.33678 & 0.30854 \\
\hline & $Q_{a 2}$ & 1.46724 & 0.85749 \\
\hline & $\beta_{1}$ & 4.84694 & 0.37261 \\
\hline & $\beta_{2}$ & -496.566 & 0.00121 \\
\hline & $Q_{b 1}$ & 0.53699 & 0.00165 \\
\hline & $Q_{b 2}$ & 0.97140 & 37.81123 \\
\hline & $\gamma_{1}$ & 6.78845 & 2.17693 \\
\hline & $\gamma_{2}$ & -446.43681 & 44.29724 \\
\hline & $\alpha_{1}$ & -2.10759 & -44.3262 \\
\hline & $a$ & 0.28100 & -0.2427 \\
\hline & $b$ & -1.74020 & 0.5471 \\
\hline & $R^{2}$ & 0.9768 & 0.9668 \\
\hline & SSE & 0.27969 & 0.14819 \\
\hline \multirow{12}{*}{ Model 2} & $Q_{a 1}^{\backslash}$ & 17.6611 & 0.07986 \\
\hline & $Q_{a 2}^{\backslash}$ & 0.09999 & 0.11920 \\
\hline & $Q_{b 1}^{\backslash}$ & 0.00199 & 0.00192 \\
\hline & $Q_{b 2}^{\backslash}$ & 2.95984 & 2.79537 \\
\hline & $\alpha_{1}$ & -0.00411 & -0.00290 \\
\hline & $a_{1}$ & $7.80 \times 10^{-6}$ & $-3.10 \times 10^{-3}$ \\
\hline & $b_{1}$ & $4.999 \times 10^{-5}$ & -0.38191 \\
\hline & $\alpha_{2}$ & 0.30885 & 0.48269 \\
\hline & $a_{2}$ & 0.74212 & 0.88575 \\
\hline & $b_{2}$ & -0.13349 & -0.26469 \\
\hline & $R^{2}$ & 0.9868 & 0.9838 \\
\hline & SSE & 0.08514 & 0.06639 \\
\hline
\end{tabular}

$$
\text { Model 2: } q_{e}=\frac{\frac{\left.Q_{a 1}^{\backslash}+\left(Q_{a 2}\right\rfloor_{2} b_{1}\right)}{1+b_{1}} b_{1} C_{e}}{1+b_{1} C_{e}}+\frac{\frac{Q_{b 1}+\left(Q_{b 2} * b_{2}\right)}{1+b_{2}} b_{2} C_{e}}{1+b_{2} C_{e}}
$$

where $b_{1}$ and $b_{2}$ are the affinities of the first and second functional groups, respectively.

$$
b_{1}(p H, T)=e^{\left(\frac{\alpha_{1}}{T}\right)+a_{1} p H+b_{1}}, b_{2}(p H, T)=e^{\left(\frac{\alpha_{2}}{T}\right)+a_{2} p H+b_{2}}
$$

where $\beta_{1}, \beta_{2}, \gamma_{1}, \gamma_{2}, \alpha_{1}, \alpha_{2}, a_{1}, a_{2}, b_{1}$ and $b_{2}$ are constants.

The experimental data $\left(q_{e}\right.$ as a function of $C_{e}$ ) are obtained at different values of $\mathrm{pH}$ and temperature. These data were fitted by a non-linear regression method [37] to evaluate the adjustable constants $\left(\beta_{1}, \beta_{2}, \gamma_{1}, \gamma_{2}, \alpha_{1}, \alpha_{2}, a_{1}, a_{2}, b_{1}\right.$ and $\left.b_{2}\right)$, by minimizing the sum of the squared deviations between experimental and predicted values. Fig. 2 is explained the scatter diagram obtained by plotting values of $q_{e}$ predicted by the Bi-Langmuir model (Models 1 and 2) in comparison with experimental data where the 45 degree line is usually drawn to facilitate interpretation of the scatter plot.
Table 2 presents the fitted constants of the developed models together with the statistical measures. This table in combination with Fig. 2 certified that the Model 2 is more representative in the description of measured sorption data and can be incorporated in the future with solute transport equation to describe the migration of contaminant in continuous mode.

\subsection{Fourier Transform Infrared (FTIR) Analysis}

This analysis is considered an important test that can be used to identify the effective functional groups [38] responsible of the binding between the cadmium ions and sites on the WFS in the sorption process. Shimadzu FTIR (8000 series spectrophotometers) with the infrared spectra ranged from 400 to 4000 $\mathrm{cm}^{-1}$ was used to address the change in the transmittance for WFS sample after sorption of cadmium ions as plotted in Fig. 3 for initial $\mathrm{pH}$ equal to 4 and 5 . The shifts in the infrared frequencies of bonds (O-H band, $\mathrm{H}-\mathrm{O}-\mathrm{H}, \mathrm{O}-\mathrm{Si}-\mathrm{O}$, and $\mathrm{Si}-\mathrm{O}$ band) are the main groups for enhancement the binding of cadmium onto WFS with the wavenumbers values at $3,619,1,668,662$, and $522 \mathrm{~cm}^{-1}$, respectively [39, 40]. These numbers signified that the surface silanol groups (O-H band) are weak acids [41]. The change in the hydroxide group is due to formation of cadmium hydroxide $(\mathrm{pH}>4.5)$ and the change in $\mathrm{Si}-\mathrm{O}$ due to adsorption cadmium as following:

$$
\begin{gathered}
\text { For initial } \mathrm{pH}<4.5 ; \mathrm{Si}-\mathrm{OH}+\mathrm{Cd}^{+2} \rightarrow \mathrm{Si}-\mathrm{OCd}+\mathrm{H}^{+} \\
\qquad \mathrm{SiO}(\mathrm{OH})+\mathrm{Cd}^{+2} \rightarrow \operatorname{SiO}(\mathrm{OC} d)+\mathrm{H}^{+}
\end{gathered}
$$

For initial pH $>4.5 ; \mathrm{Si}-\mathrm{OH}+\mathrm{Cd}(\mathrm{OH})^{+} \rightarrow \mathrm{Si}-\mathrm{OCd}(\mathrm{OH})+\mathrm{H}^{+}(28)$

$$
\mathrm{SiO}(\mathrm{OH})+\mathrm{Cd}(\mathrm{OH})^{+} \rightarrow \mathrm{O}-\mathrm{SiO}(\mathrm{OCd}(\mathrm{OH}))+\mathrm{H}^{+}
$$

The sorption mechanism causes an increase in the absolute difference between values of final $\mathrm{pH}$ for contaminated and uncontaminated (control) aqueous solutions due to interaction with WFS as shown in Fig. 4. Hence, the results of this test are consistent with the assumptions of the developed models described in the earlier section. In addition, Table 3 explains the variation of final $\mathrm{pH}$ for contaminated and control aqueous solutions as a function of the initial $\mathrm{pH}$. It is clear that the final $\mathrm{pH}$ of control (uncontaminated) solution is greater than that of contaminated solution because of the dissolution of $\mathrm{CaO}$; however, the low values of the final $\mathrm{pH}$ for contaminated solution may be due to release of $\mathrm{H}^{+}$ions according to Eq. (26)-(29).

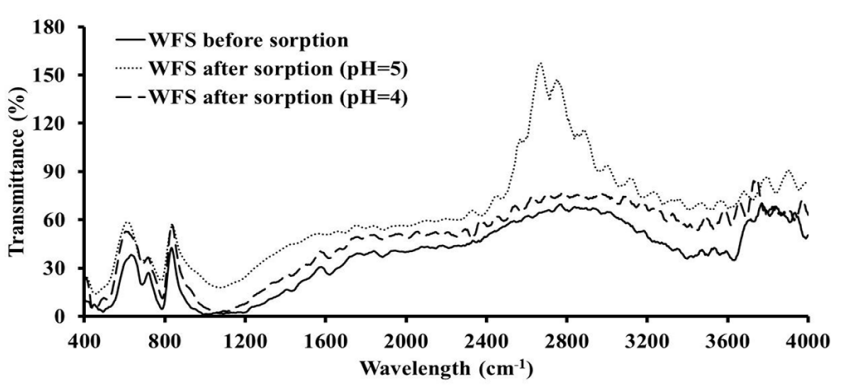

Fig. 3. FTIR test for WFS before and after sorption of cadmium for two values of initial $\mathrm{pH}$. 


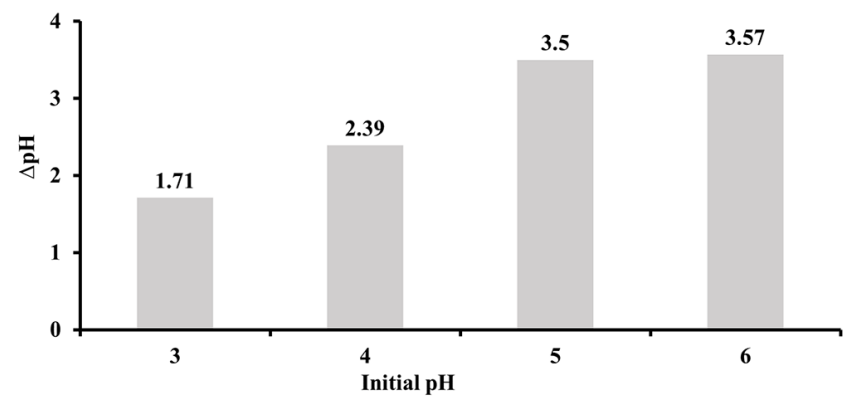

Fig. 4. The absolute difference between values of final $\mathrm{pH}$ for contaminated and uncontaminated (control) aqueous solutions due to interaction with WFS.

Table 3. Variation of Final $\mathrm{pH}$ for Contaminated and Uncontaminated (control) Aqueous Solutions Due to Interaction with WFS as Function to Initial $\mathrm{pH}$

\begin{tabular}{c|c|c|}
\hline \multirow{2}{*}{ Initial pH } & \multicolumn{2}{|c}{ Final pH } \\
\cline { 2 - 3 } & Uncontaminated solution & Contaminated solution \\
\hline 3 & 7.15 & 5.44 \\
4 & 8.24 & 5.85 \\
5 & 9.32 & 5.82 \\
6 & 9.4 & 5.83 \\
\hline
\end{tabular}

\section{Conclusions}

An isotherm expression was developed for simulating initial $\mathrm{pH}$ and temperature-dependent sorption effects. Langmuir model was the base expression used for achieving the development process, thereby allowing the variation of the maximum adsorption capacity and affinity constant in response to changes in the initial $\mathrm{pH}$ and temperature values. The two forms of developed Langmuir model were derived depending on the number of acidic functional groups and the affinity of metal ions regarding the reactive material. Further, the validity of these models was tested based on the experimental results of cadmium sorption onto WFS for different values of initial $\mathrm{pH}$ and temperature. The results proved that the Model 2 for two weakly acidic functional groups with different affinity has a great ability in the description of sorption data as a function of initial $\mathrm{pH}$ and temperature with the coefficient of determination $\left(\mathrm{R}^{2}\right)$ not less than 0.9838 and SSE not greater than 0.08514. This result was satisfied with output of FTIR test which reveals the sorption process can be achieved due to the presence of more than one acidic functional group.

\section{References}

1. Fergusson JE. The heavy elements: Chemistry, environmental impact and health effects. $1^{\text {st }}$ eds. Oxford: Pergamon Press; 1990.

2. Peng JF, Song YH, Yuan P, Cui XY, Qiu GL. The remediation of heavy metals contaminated sediment. J. Hazard. Mater.
2000;161:633-640.

3. Nriagu JO. A global assessment of natural sources of atmospheric trace metals. Nature 1989;338:47-49.

4. He ZL, Yang XE, Stoffella PJ. Trace elements in agroecosystems and impacts on the environment. J. Trace Elem. Med. Biol. 2005;19:125-140.

5. Gibert O, Cortina JL, de Pablo J, Ayora C. Performance of a field-scale permeable reactive barrier based on organic substrate and zero-valent iron for in situ remediation of acid mine drainage. Environ. Sci. Pollut. Res. 2013;20:7854-7862.

6. Wołejko E, Pawluśkiewicz B, Wydro U, Łoboda T, Butarewicz A. The effect of sewage sludge on the growth and species composition of the sward and the content of heavy metals in plants and urban soil. Land Reclam. 2014;46:101-114.

7. Mazur Z, Radziemska M, Fronczyk J, Jeznach J. Heavy metal accumulation on pollution bio-indicators in urban areas of north-east Poland. Fresen. Environ. Bull. 2015;24:216-223.

8. Radziemska M, Fronczyk J. Level and contamination assessment of soil along an expressway in an ecologically valuable area in Central Poland. Int. J. Environ. Res. Public Health. 2015;12:13372-13387.

9. Adamcova D, Radziemska M, Ridoškova A, et al. Environmental assessment of the effects of a municipal landfill on the content and distribution of heavy metals in Tanacetum vulgare $\mathrm{L}$. Chemosphere 2017;185:1011-1018.

10. Mieles J, Zhan H. Analytical solutions of one-dimensional multispecies reactive transport in a permeable reactive barrier-aquifer system. J. Contam. Hydrol. 2012;134-135:54-68.

11. Bartzas G, Komnitsas K. Solid phase studies and geochemical modelling of low-cost permeable reactive barriers. J. Hazard. Mater. 2010;183:301-308.

12. Ghosh MM. Adsorption of inorganic arsenic and organo-arsenical on hydrous oxides. In: Patterson, JW, and Passino, R, eds. Metals speciation, separation, and recovery. Chelsea: Lewis Publishers; 1989;6:499-518.

13. Wankasi D, Tarawou T. Studies on the effect $\mathrm{pH}$ on the sorption of $\mathrm{Pb}(\mathrm{II})$ and $\mathrm{Cu}(\mathrm{II})$ ions from aqueous media by Nipa Palm (Nypa Fruticans Wurmb). J. Appl. Sci. Environ. Manage. 2008;12:87-94.

14. Hsia TH, Lo SL, Lin CF. As(V) adsorption on amorphous iron oxide: Triple layer modelling. Chemosphere 1992;25:1825-1837.

15. Yu Q, Kaewsarn P. A model for $\mathrm{pH}$ dependent equilibrium of heavy metal biosorption. Korean J. Chem. Eng. 1999;16:753-757.

16. Vegliò F. Modelling of equilibrium heavy metal biosorption data at different $\mathrm{pH}$ : A possible methodological approach. Eur. J. Min. Proc. Environ. Prot. 2003;3:49-57.

17. Gheju M, Iovi A, Balcu I. Hexavalent chromium reduction with scrap iron in continuous-flow system: Part 1: Effect of feed solution pH. J. Hazard. Mater. 2008;153:655-662.

18. Jeppu GP, Clement TP. A modified Langmuir-Freundlich isotherm model for simulating $\mathrm{pH}$-dependent adsorption effects. J. Contam. Hydrol. 2012;129-130:46-53.

19. Faisal AAH. Effect of $\mathrm{pH}$ on the performance of olive pips reactive barrier through the migration of copper-contaminated groundwater. Desalin. Water Treat. 2016;57:4935-4943.

20. Fu H, Li X, Wang J, et al. Activated carbon adsorption of quinolone antibiotics in water: Performance, mechanism, and 
modeling. China J. Environ. Sci. 2017;56:145-152.

21. Graham D. The characterization of physical adsorption systems: I. The equilibrium function and standard free energy of adsorption. J. Phys. Chem. 1953;57:665-669.

22. Ho YS, Porter JF, McKay G. Equilibrium isotherm studies for the sorption of divalent metal ions onto peat: Copper, nickel and lead single component systems. Water Air Soil Pollut. 2002;141:1-33.

23. Hamdaoui O, Naffrechoux E. Modeling of adsorption isotherms of phenol and chlorophenols onto granular activated carbon part I. Two-parameter models and equations allowing determination of thermodynamic parameters. J. Hazard. Mater. 2007;147:381-394.

24. Vijayaraghavan K, Padmesh TVN, Palanivelu K, Velan M. Biosorption of nickel(II) ions onto sargassum wightii: Application of two-parameter and three-parameter isotherm models. J. Hazard. Mater. 2006;133:304-308.

25. Naushad M, AL-Othman ZA, Islam M. Adsorption of cadmium ion using a new composite cation-exchanger polyaniline Sn(IV) silicate: Kinetics, thermodynamic and isotherm studies. Int. J. Environ. Sci. Technol. 2013;10:567-578.

26. Naushad M. Surfactant assisted nano-composite cation exchanger: Development, characterization and applications for the removal of toxic $\mathrm{Pb}^{2+}$ from aqueous medium. Chem. Eng. J. 2014;235:100-108.

27. Madala S, Nadavala SK, Vudagandla S, Boddu VM, Abburi K. Equilibrium, kinetics and thermodynamics of cadmium(II) biosorption onto composite chitosan biosorbent. Arab. J. Chem. 2017;10:S1883-S1893.

28. Faisal AAH, Naji LA. Simulation of ammonia nitrogen removal from simulated wastewater by sorption onto waste foundry sand using artificial neural network. Assoc. Arab Univ. J. Eng. Sci. 2019;26:28-34.

29. Heidmann I, Christl I, Leu C, Kretzschmar R. Competitive sorption of protons and metal cations onto kaolinite: experiments and modeling. J. Colloid Interf. Sci. 2005;282:270-282.

30. Faisal AAH, Ahmed MD. Remediation of groundwater contaminated with copper ions by waste foundry sand permeable barrier. J. Eng. 2014;20:62-77.

31. Faisal AAH, Hmood ZA. Groundwater protection from cadmium contamination by zeolite permeable reactive barrier. Desalin. Water Treat. 2015;53:1377-1386.

32. Rashid HM, Faisal AAH. Removal of dissolved trivalent chromium ions from contaminated wastewater using locally available raw scrap iron-aluminum waste. Al-Khwarizmi Eng. J. 2019;15:134-143.

33. Naushad M, Mittal A, Rathore M, Gupta V. Ion-exchange kinetic studies for $\mathrm{Cd}(\mathrm{II}), \mathrm{Co}(\mathrm{II}), \mathrm{Cu}(\mathrm{II})$, and $\mathrm{Pb}(\mathrm{II})$ metal ions over a composite cation exchanger. Desalin. Water Treat. 2015;54: 2883-2890.

34. Scheckel KG, Sparks DL. Temperature effects on nickel sorption kinetics at the mineral-water interface. Soil Sci. Soc. Am. J. 2001;65:719-728.

35. Al-Ghouti M, Khraisheh MAM, Ahmad MNM, Allen S. Thermodynamic behaviour and the effect of temperature on the removal of dyes from aqueous solution using modified diatomite: A kinetic dtudy. J. Colloid Interf. Sci. 2005;287:6-13.

36. Aksu Z. Determination of the equilibruim, kinetic and thermodynamic parameters of the batch biosorption of nickel(II) ions onto chlorella vulgaris. Proc. Biochem. 2002;38:89-99.

37. Brown AM. A step-by-step guide to non-linear regression analysis of experimental data using a microsoft excel spreadsheet. Comput. Meth. Prog. Biomed. 2001;65:191-200.

38. Naushad M, Ahamad T, Al-Maswari B, Alqadami AA, Alshehri SM. Nickel ferrite bearing nitrogen-doped mesoporous carbon as efficient adsorbent for the removal of highly toxic metal ion from aqueous medium. Chem. Eng. J. 2017;330:1351-1360.

39. Alkan M, Kalay B, Doğan M, Demirbaş Ō. Removal of copper ions from aqueous solutions by kaolinite and batch design. J. Hazard. Mater. 2008;153:867-876.

40. Carnin RLP, Folgueras MV, Luvizão RR, Correia SL, da Cunha CJ, Dungan RS. Use of an intergated approach to characterize the physicochemical properties of foundry green sands. Thermochim. Acta. 2012;543:150-155.

41. Yong RN. Geoenvironmental engineering: Contaminated soils, pollutant fate and mitigation. Boca Raton: CRC Press; 2000. 